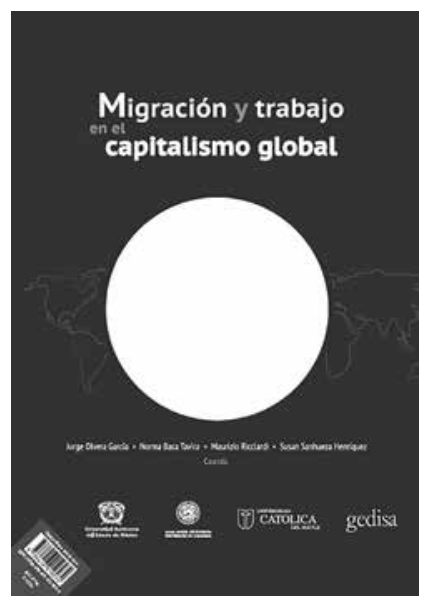

From a Philosophical to a Sociological Approach: The Various Faces of Migration in the Context of Globalization

María del Socorro Castañeda Díaz Universidad Autónoma del Estado de México, Toluca, Estado de México, México maria.castaneda.diaz@gmail.com

Desacatos 59 , enero-abril 2019, pp. 196-201
- Migración y trabajo en el

capitalismo global

Jorge Olvera García, Norma Baca

TAVIRA, MAURIZIO RICCIARDI Y SUSAN

SANHUEZA Henriquez (COORDS.), 2017

Gedisa/Universidad Autónoma del

Estado de México/Università di

Bologna/Universidad Católica del Maule,

Toluca

\section{De lo filosófico a lo social: las facetas de la migración en el contexto de la globalización}

\author{
MARÍA DEL SOCORRO CASTAÑEDA DÍAZ
}

a migración es un fenómeno complejo que se vive de maneras diversas en cada región del planeta y presenta casi tantas variaciones como rutas migratorias existen. Para comprenderlo mejor, es necesario que los especialistas unan esfuerzos y realicen trabajos conjuntos que contribuyan a ampliar la visión del asunto. Éste es el caso de Migración y trabajo en el capitalismo global, una publicación bilingüe, coeditada por Gedisa, la Universidad Autónoma del Estado de México, la Universidad de Bolonia, Italia, y la Universidad Católica del Maule, Chile.

En ocho capítulos, escritos por 12 autores de nacionalidades diversas, se muestran algunas de las facetas de la migración y los modos en los que puede estudiarse. El recorrido va desde la teoría política de las migraciones hasta un estudio sobre la apreciación de la prensa escrita sobre las personas migrantes. La publicación, coordinada por Jorge Olvera García, Norma Baca Tavira, Maurizio Ricciardi y Susan Sanhueza, muestra la migración en una gama de contextos. 
Comienza con la propuesta de Maurizio Ricciardi, de la Universidad de Bolonia, que habla sobre "Migrantes, poder y capital. Acerca de la teoría política de las migraciones". El especialista describe al migrante como una antinomia en el funcionamiento ordenado del Estado y la sociedad; los migrantes resultan sujetos o no de integración, según sus posibilidades específicas de acceso a los ingresos económicos y los servicios. Ricciardi expresa la necesidad de proponer una teoría política de las migraciones alejada de moralismos, sobre todo, capaz de establecer los límites de un discurso que explique cómo los movimientos migratorios reforman en los hechos tanto a las instituciones como a las relaciones de poder, y transforman también los conceptos fundamentales de la política moderna.

Asimismo, enfatiza cómo en la actualidad estamos ante un regreso continuo de los nacionalismos, cuya legitimación sucede a partir de la política de las migraciones. Estos nacionalismos son resultado de políticas de la estatualidad global, es decir, "están centrados en la fragmentación neoliberal de la ciudadanía” (p. 30). Los migrantes "no son los sujetos de una ciudadanía en devenir, sino los síntomas vivientes de una fragmentación neoliberal al interior del Estado global" (p. 30). El investigador propone que “el 'Estado global se gobierna a sí mismo gobernando las migraciones', en la medida en que estas últimas, como movimiento social, imponen dinámicas, códigos y tiempos no previstos" (p. 37).

Por su parte, Alejandro I. Canales, de la Universidad de Guadalajara, México, en "Migración y trabajo en escenario de poscrisis en Estados Unidos de América. Polarización ocupacional y racialización de la desigualdad social", describe las maneras de discriminación laboral que viven los migrantes latinos en Estados Unidos y cómo su condición étnica y migratoria los expone a una situación de vulnerabilidad social y política que se refleja, por ejemplo, en discriminación salarial y precariedad laboral, entre otras situaciones. Este trabajo consiste en el análisis de la inserción de los migrantes latinoamericanos en puestos de trabajo en Estados Unidos, en un escenario posterior a la crisis de 2008. El especialista apunta la existencia de un déficit estructural de mano de obra en ese país como una condición que promueve la inmigración e involucra de manera directa a los latinoamericanos. Este déficit, especifica, es la diferencia entre el volumen de puestos de trabajo que produce al año la economía y el volumen de la población originaria económicamente activa, que disminuye a causa del envejecimiento.

Canales explica que en Estados Unidos hay una diferenciación de las ocupaciones, situación que afecta a los trabajadores de modo distinto de acuerdo con su condición tanto étnica como migratoria. Explica que se trata de una racialización de la desigualdad social y ocupacional, y con base en ella, los cargos que están arriba en la jerarquía son ocupados en su mayoría por trabajadores blancos, mientras los puestos de menor rango, en la base de la pirámide, son asignados a los latinos y otras minorías.

Por medio de un análisis estadístico detallado, basado en una clasificación de las ocupaciones, el investigador demuestra que "la crisis ha tendido a reforzar las tendencias a la polarización del empleo, profundizando los patrones de desigualdad y diferenciación étnica de la estructura ocupacional” (p. 51).

Así, un estudio de datos entre los que se consideran, por ejemplo, las remuneraciones promedio según grandes grupos de ocupación, evidencia la desigualdad en el mercado laboral estadounidense, en el que se vive un proceso profundo de polarización, en el cual los patrones de inserción laboral de los trabajadores se relacionan de manera directa con su origen étnico-migratorio. Según el investigador, en Estados Unidos "ni los blancos se enfrentan seriamente al riesgo de descender en la pirámide ocupacional, ni los latinos tienen mayor opción de ascender en la jerarquía laboral” (p. 66).

En su oportunidad, Dídimo Castillo Fernández, de la Universidad Autónoma del Estado de 
México, en el capítulo “¿Es posible el desarrollo en América Latina hoy? El nuevo entorno de la 'desglobalización"”, plantea el desarrollo como "un concepto referencial general que describe, aunque no explica, un estado o estadio dentro de otros posibles" (p. 76). El desarrollo, dice, no señala una condición específica, sino un estado de cosas y la existencia de una posibilidad de transformación. El investigador establece con claridad la postura de que "no habrá desarrollo sin un cambio de modelo económico" (p. 79), y menciona que con la economía globalizada se restablecieron formas de explotación, dependencia y gestión del trabajo, situaciones que se pensaba que habían sido superadas.

En su texto, lleva al lector a un recorrido que empieza en la crítica dependentista y termina en la teoría del desarrollo, para luego profundizar en tres puntos fundamentales: la globalización, el Estado nacional y las nuevas condiciones para el desarrollo. La globalización, señala:

Socavó las fronteras nacionales, y con ello, erosionó la estructura interna de los Estados nacionales, al promover la libre circulación de mercancías y capitales, aunque no fue homogeneizadora como se preveía; por el contrario, engendró resultados distintos en los diversos países y regiones. Lo regional reemergió, a pesar o a causa de la globalización (p. 86).

Tras un análisis profundo del neoliberalismo, Castillo explica lo que llama "nuevo entorno de la desglobalización”, es decir, el escenario político estadounidense después del triunfo de Donald Trump que, afirma, comienza a fomentar la reversión de la globalización neoliberal y el impulso de la industrialización en el país.

A su vez, Norma Baca Tavira y Rosa Patricia Román Reyes, de la Universidad Autónoma del Estado de México, en su contribución “Tensiones teóricas y metodológicas en la medición de la migración internacional en América Latina", exponen la necesidad de que el estudio de las migraciones y las movilidades cuestione, construya y reconstruya los enfoques teóricos y metodológicos de manera dinámica, pues las propias migraciones "son muy diversas y plurales, por lo que el desarrollo de un solo marco analítico-teórico explicativo es una quimera" (p. 99).

A partir de esta aseveración, proponen el estudio de los fenómenos migratorios desde la perspectiva de la racionalidad. Van más allá cuando plantean que el análisis de las migraciones debe incluir las teorías sociales y lo social. En este punto, mencionan algunos estudios sobre redes sociales, otros relativos a la migración en cadena y tocan algunos aspectos de la teoría circular acumulativa aplicada a la migración.

En su trabajo explican la importancia de las mediciones, no sin aclarar que el fenómeno migratorio también es difícil de cuantificar, y dedican una amplia exposición sobre la encuesta como herramienta analítica central de acercamiento a la migración. Asimismo, sugieren estudiar el fenómeno desde el punto de vista cualitativo, dado que la combinación de ambas perspectivas permitiría ahondar "en las construcciones individuales de las condiciones y percepciones de la migración que se realizan y reproducen sobre bases diferenciadas pero conectadas, autónomas pero interdependientes" (p. 110). Esta necesidad de combinar elementos teóricos y metodológicos, concluyen, implicaría entrar en un terreno de interdisciplinariedad y metodología que podría representar el principio de un camino hacia la mirada integral de las migraciones.

En "Sistema contemporáneo de migración laboral y gestión en Europa", Rutvica Andrjiasevic, de la Universidad de Bristol, Reino Unido, y Devi Sacchetto, de la Universidad de Padua, Italia, explican cómo la Unión Europea (UE) es, al mismo tiempo, un grupo de Estados-nación y un espacio con libertad de circulación, considerado uno de 
los principales derechos de los ciudadanos comunitarios. Argumentan que quienes apoyan la integración europea ven la movilidad laboral como un elemento potencialmente benéfico, porque favorece, entre otras cosas, tanto a los países expulsores como a los receptores, y también beneficia a los trabajadores que emigran, pues les permite dar valor al capital humano y reducir las desigualdades entre los Estados que integran la UE.

El capítulo se refiere al estudio de caso de la migración laboral de la empresa Foxconn hacia la República Checa, donde la movilidad de la fuerza de trabajo se basa en las posibilidades del mercado de trabajo en la UE, para satisfacer el anhelo personal de mejorar la condición social y laboral. El análisis parte del punto de vista de la autonomía de las migraciones, en la cual la migración se considera una vía para salir en colectivo de ambientes en los que el movimiento de los trabajadores está controlado por el capital o el Estado. Las autoras señalan que al emigrar, los trabajadores utilizan a su favor el espacio de la UE, comparan las condiciones laborales y los sueldos, emplean la movilidad y la provisionalidad para alejarse de situaciones adversas de vida y trabajo.

También identifican las trayectorias de la movilidad del trabajo en la Europa ampliada y los flujos migratorios multidireccionales, asociados a las políticas que regulan el mercado de trabajo. Con base en su investigación, proponen el término trabajador multinacional, que representa una nueva fuerza de trabajo de bajo costo, cuyas prácticas, basadas en la temporalidad y la movilidad, contrastan con lo que los patrones esperan de ellos. Como colofón, abren un debate acerca del reto teórico y político que representan estos trabajadores multinacionales, con formas de agregación y organización que requieren ser analizadas, en particular porque todavía se están construyendo.

Por su parte, Cristina Pizzonia, de la Universidad Autónoma Metropolitana-Xochimilco, en "De Rusia con dolor. La migración rusa tras la caída del Bloque Soviético", pone en la mesa de análisis un tema que tiene vigencia, aunque han pasado 25 años, porque el fenómeno migratorio continúa, aunque a un ritmo e intensidad diferentes. La investigadora sugiere un análisis que incluye las condiciones demográficas, políticas, económicas y laborales que tienen que ver con la migración de ciudadanos de la Federación Rusa hacia casi todos los países del planeta.

"Los 25 años posteriores a la URSS encuentran una nueva configuración mundial, así como una agenda política en redefinición, lo que influye directamente en los procesos migratorios", afirma (p. 43), y expone la condición económica y social de la Federación Rusa, que hoy es uno de los principales países de expulsión y recepción de migrantes del mundo, con Estados Unidos, Ucrania y la India.

Rusia registra relaciones migratorias en todo el orbe. En su territorio hay migrantes procedentes de 150 países y sus emigrantes están presentes en 101 naciones. Los flujos migratorios desde y hacia $\mathrm{Ru}-$ sia son motivados por situaciones étnicas, de movimientos de refugiados y etnoculturales. Pizzonia denomina esta dinámica migratoria como la diáspora rusa, que puede o no caracterizarse por medio de un sistema migratorio. Expone algunas situaciones en la Federación Rusa en las que las nuevas generaciones, que no crecieron durante la época soviética, no añoran un sistema que no conocieron, pero, además, no tienen la misma calidad educativa de quienes se formaron entonces. Asimismo, menciona que los conflictos entre las repúblicas que formaban la Unión Soviética continuarán contribuyendo a la existencia de flujos migratorios intensos. La situación actual de la Federación Rusa no permite definir con claridad un sistema de migraciones que la caractericen, incluso cuando hay una continuidad en los movimientos de población.

Enrica Rigo, de la Universidad Roma Tre, en “¿Qué clase de asilo? Mujeres y protección internacional en la crisis de las fronteras europeas", expone 
una cuestión que presenta una crisis creciente en Italia. La investigadora afirma que el asilo se ha convertido en un tema político. Para resignificar el derecho a éste, los migrantes lo convierten en un instrumento para acceder al territorio, o bien, obtener un estatus jurídico regular. En particular, en Italia, entre 2014 y 2015, las solicitudes de asilo incrementaron cerca de 30\%. En el mismo periodo, el número de mujeres aspirantes casi se duplicó. Rigo explica que, además, hay un aumento significativo de mujeres nigerianas en busca de asilo — 400\%, según reportes de la Organización Internacional de las Migraciones (OIM)—, quienes con frecuencia son víctimas potenciales de trata.

La investigadora analizó los procedimientos para otorgar protección internacional a 56 nigerianas que solicitaron asilo en Italia desde 2014. Se trata de un trabajo cualitativo que pretende, entre otros motivos, hallar "un enfoque hacia el derecho lleno de realismo radical, cuyas raíces pueden —ademásser buscadas en la teoría jurídica feminista” (p. 170). $\mathrm{Al}$ cuestionar qué clase de protección reciben las nigerianas de su estudio, Rigo menciona que "la violencia típicamente perpetrada contra las mujeres, como en el caso de la trata con la finalidad de explotación sexual, tiene dificultades para ser puesta como fundamento de las resoluciones de reconocimiento de la protección internacional" (p. 182). Así, nos pone de frente una situación compleja:

Las mujeres que huyen a través del mediterráneo no son nunca víctimas de un solo verdugo: huyen del patriarcado, de los conflictos, de sus mismos reclutadores y de la industria del sexo, de los traficantes, y no menos importante, del régimen de las fronteras europeas que, impidiéndoles la fuga, quisiera ligarlas a su condición de víctimas (p. 183).

En el último capítulo, Susan Sanhueza Henríquez, de la Universidad Católica del Maule; Francisco Checa y Olmos, de la Universidad de Almería,
España, y Miguel Friz Carrillo, de la Universidad del Bío-Bío, Chile, muestran otra de las facetas posibles en el estudio de las migraciones. En el texto "España y Chile en sus inicios migratorios: una aproximación desde la prensa escrita", los investigadores dan a conocer los resultados de un análisis documental en el que compararon las realidades migratorias de dos países desde el punto de vista de algunas publicaciones periodísticas.

Éste es un trabajo binacional que permite observar cómo la percepción de los migrantes puede ser influida por ciertos prejuicios étnicos a partir del impacto de la información publicada en los medios de comunicación. Tanto España como Chile, por diversos factores y en distintas circunstancias, son países con perfiles migratorios importantes. Los investigadores muestran cómo los medios de comunicación en general y la prensa escrita en particular "reelaboran, a través del discurso periodístico, las identidades de las comunidades receptora y migrante", al mismo tiempo que "hacen eco de los discursos que emergen desde distintos sectores del poder, modelando con ello las percepciones, actitudes y actuaciones de la población” (p. 191).

Para el caso de España, analizaron 3319 noticias; para Chile, otras 165 . Hicieron una valoración de las connotaciones positivas o negativas de la información publicada sobre migración y definieron cuatro categorías principales: los migrantes como amenaza de invasión, la inmigración como portadora de elementos negativos/positivos para la sociedad receptora, las condiciones de vida de los migrantes y las actitudes racistas y xenófobas hacia la población migrante.

En los cuatro casos, los resultados muestran que la prensa presenta noticias sobre los migrantes que, si bien no son todas negativas, sí tienen esa tendencia cuando se tratan temas relacionados con el trabajo, la vivienda o los permisos de residencia y laborales, mientras en los tópicos superficiales, como el folclor o la gastronomía, los inmigrantes 
son tratados de forma positiva. Se concluye que en la información que publican los medios existe "un enfoque del fenómeno inmigratorio como un problema social asociado a la violencia, la delincuencia, el prejuicio, los estereotipos o las actitudes racistas" (p. 187).

Con la visión de investigadores de dos continentes, este libro muestra que la migración dista mucho de ser un objeto de estudio limitado y definido, por el contrario, queda como objeto de análisis desde disciplinas y perspectivas diversas. Se trata de un trabajo que involucra no sólo la visión de contextos contrastantes, también incluye varios campos de estudio, como la filosofía política, la comunicación o la sociología. Ante este esfuerzo, no queda sino reflexionar acerca de la necesidad inminente de fomentar estudios transversales, inter e intradisciplinarios, que conjunten esfuerzos académicos internacionales para profundizar en temas trascendentales que son parte de la realidad actual. D 